Biochem Soc Trans. 2008 April ; 36(Pt 2): 229-234. doi:10.1042/BST0360229.

\title{
Integrin activation
}

\author{
Asoka Banno and Mark H. Ginsberg ${ }^{1}$ \\ Department of Medicine, University of California, San Diego, 9500 Gilman Drive, MC 0726, San \\ Diego, CA 92093-0726, U.S.A.
}

\begin{abstract}
Agonist stimulation of integrin receptors, composed of transmembrane $\alpha$ and $\beta$ subunits, leads cells to regulate integrin affinity ('activation'), a process that controls cell adhesion and migration, and extracellular matrix assembly. A final step in integrin activation is the binding of talin to integrin $\beta$ cytoplasmic domains. We used forward, reverse and synthetic genetics to engineer and order integrin activation pathways of a prototypic integrin, platelet $\alpha \operatorname{Ilb} \beta 3$. PMA activated $\alpha \operatorname{IIb} \beta 3$ only after expression of both PKC $\alpha$ (protein kinase $\mathrm{C} \alpha$ ) and talin at levels approximating those in platelets. Inhibition of Rap1 GTPase reduced $\alpha \mathrm{Ilb} \beta 3$ activation, whereas expression of constitutively active Rap1A(G12V) bypassed the requirement for PKC $\alpha$. Overexpression of a Rap effector, RIAM (Rap1GTP-interacting adaptor molecule), activated $\alpha \operatorname{IIb} \beta 3$ and bypassed the requirement for PKC $\alpha$ and Rap1. In addition, shRNA (short hairpin RNA)-mediated knockdown of RIAM blocked talin interaction with and activation of integrin $\alpha \operatorname{IIb} \beta 3$. Rap1 activation caused the formation of an 'activation complex' containing talin and RIAM that redistributed to the plasma membrane and activated $\alpha \operatorname{IIb} \beta 3$. The central finding was that this Rap1-induced formation of an 'integrin activation complex' leads to the unmasking of the integrin-binding site on talin, resulting in integrin activation.
\end{abstract}

\section{Keywords}

cell adhesion; integrin; Rap1; signal transduction; talin; thrombosis

\section{Integrin receptors}

Integrin adhesion receptors are glycosylated heterodimers composed of non-covalently associated type I transmembrane $\alpha$ and $\beta$ subunits [1-3]. Each subunit contains a large extracellular domain ( $\mathrm{N}$-terminus of $>700$ residues), a single transmembrane domain ( $>20$ residues) and a usually short cytoplasmic domain (C-terminus of 13-70 residues). Membraneproximal regions of the cytoplasmic tails are well conserved in most integrin subunits, and the boundary between the transmembrane and cytoplasmic domains is assumed to lie between the conserved tryptophan/tyrosine and lysine/arginine residues [4,5]. This conserved lysine/ arginine residue is followed by a stretch of four to six apolar residues, resulting in ambiguity about the beginning of the integrin cytoplasmic domain $[4,5]$. The membrane-proximal sequences GFFKR and LLXXXHDRRE are conserved in the $\alpha$ and $\beta$ subunits respectively $[4,5]$.

Many integrins are expressed and remain in a low-affinity binding state until cellular stimulation transforms them into a high-affinity form, an event that can modify cell adhesion $[6,7]$. Because information travels from the inside to the outside of the cell, this is often referred to as 'inside-out' signalling [6,8,9]. This form of signalling is often precisely regulated in time and space in settings such as platelet aggregation and leucocyte transmigration [6,10]. A major 
focus of recent research has been affinity-dependent regulation of integrin-mediated adhesion, a process that is operational as integrin activation [6-9].

\section{Extracellular rearragements}

On the basis of studies using crystallography, NMR, electron microscopy and FRET (Förster resonance energy transfer), integrins appear to assume multiple conformations [2,11-13].

Several studies suggest that the bent conformation is a low-affinity state, whereas the extended conformation is associated with a high-affinity state of integrins [12-18]. Nevertheless, the bent form can also bind ligands with high affinity [19] in some circumstances, leading researchers to propose an alternative 'deadbolt' model for inside-out activation [19,20]. Excellent studies and reviews have discussed the dynamic equilibrium among different conformational states $[13,16,21,22]$, and it is fair to conclude that the global rearrangements in integrin conformation accompanying inside-out signalling remain incompletely understood $[16,23,24]$.

\section{Transmembrane propagation}

Integrin activation requires transmission of conformational rearrangements from the cytoplasmic face to the extracellular domain, thus implicating the involvement of the integrin transmembrane domain in the signal transduction process. These regions are highly conserved between integrins and are also conserved between species [25]. Mutational analysis and computational modelling together suggest that a helical interface between the integrin $\alpha$ and $\beta$ subunit transmembrane domains stabilizes the inactive state, and suggest that disruption of this helical transmembrane interface leads to activation [26-29].

Four motions could contribute the proposed rearrangements in the transmembrane domain and the alterations of $\alpha-\beta$ transmembrane interface: separation, pistoning, twisting and hinging $[4,5,8]$. Each involves some changes in orientation of the subunits relative to one another and to the membrane. Although recent work supports the separation and the pistoning models, highresolution structures of the transmembrane domains will be required to distinguish clearly between the different models $[4,9,12]$. Helical packing of integrin transmembrane regions is likely to require specific crossing angles and in-register alignment of side-chain arrays [29]. Furthermore, the insertion of the integrin membrane-proximal domain could vary, thus shortening or lengthening the transmembrane domain and changing the number of residues buried within the lipid bilayer $[2,9,25,29]$. The pistoning model suggests that intracellular activating signals could shorten the transmembrane helix, thereby changing membrane tilt angle and register with the neighbouring helix to avoid hydrophobic mismatch with the fixed width of the membrane bilayer. This change in tilt could be the critical event in disruption of transmembrane interactions that stabilizes the low-affinity conformation, leading to integrin activation $[2,9,29]$. In support of this model, the majority of activating transmembrane mutations identified by random mutagenesis are predicted to shorten the transmembrane helix [2,29]. Changes in the length or orientation of the integrin transmembrane domain may also lead to physiological integrin activation [9].

\section{Intracellular rearrangements}

Changes in interactions and/or in the structures of the cytoplasmic domains of integrins within the membrane-proximal regions play crucial roles in integrin activation via inside-out signalling $[4,5,9,30]$. The interaction between the membrane-proximal regions of the $\alpha$ and $\beta$ subunits is believed to be stabilized by a salt bridge between a conserved arginine residue in the $\alpha$ tail and an aspartate residue in the $\beta$ tail and by the hydrophobic residues immediately $\mathrm{N}$-terminal to the arginine and aspartate residues [10,30,31]. This association between the $\alpha$ and $\beta$ subunits is thought to prevent integrin activation by stabilizing the low-affinity state 
[1,9,32]. Mutations that disrupt this 'clasp' lead to integrin activation, and integrins can be constitutively activated by deletion or mutations in these membrane-proximal sequences $[10$, 30,32-34]. Furthermore, replacement of the cytoplasmic transmembrane regions by heterodimeric coiled-coil peptides inactivates the receptor, and cleavage of the coiled-coil activates integrins [34-36]. These data together strongly indicate that this membrane-proximal interaction plays an essential role as a stabilizer in the association of the $\alpha$ and $\beta$ membraneproximal regions, maintaining the integrins in a low-affinity state $[2,4,9]$. The important role of $\alpha$ and $\beta$ tail interaction is further supported by FRET studies that show that activation is associated with a change in separation or orientation of $\alpha$ and $\beta$ cytoplasmic tails relative to each other [2,12].

The integrin cytoplasmic domains play a central role in integrin activation [10,33], and overexpression of particular proteins that bind to the cytoplasmic tails can result in integrin activation [10,33-35]. Binding of the adaptor, talin, to the $\beta$ cytoplasmic domain is a crucial, final step in activation of several classes of integrins [37-39]. This finding has been confirmed for $\beta 1$ [40], $\beta 2[12,41,42]$ and $\beta 3$ [43] integrins; hence, talin appears to play a general role in activating multiple classes of integrins. Moreover, a study using mice harbouring point mutations in the $\beta 3$ cytoplasmic tail provided the first in vivo evidence supporting the importance of talin binding for integrin activation in mammals [44].

Talin is a major cytoskeletal protein that co-localizes with and binds to integrins and to actin and actin-binding proteins such as vinculin [1,37-39]. It forms an antiparallel homodimer made of $\sim 270 \mathrm{kDa}$ subunits, each of which consists of an N-terminal globular head domain of $\sim 50$ $\mathrm{kDa}$ and a C-terminal rod domain of $\sim 220 \mathrm{kDa}[45,46]$. The head domain contains a FERM (4.1/ezrin/radixin/moesin) domain comprising three subdomains: F1, F2 and F3. F2 and F3 subdomains of talin bind specifically to integrin $\beta 3$ tails, although F3 shows a higher affinity than F2 [38]. In addition, expression of F3, but not F2 or other high-affinity $\beta$ tail-binding proteins, activates $\alpha \operatorname{Ilb} \beta 3$ integrins, implying that the major integrin-binding and activating fragment of talin lies within the 96-residue F3 subdomain [1,38]. Knockdown of talin expression in $\mathrm{CHO}$ (Chinese-hamster ovary) cells inhibits the activation of both $\beta 1$ and $\beta 3$ integrins without altering integrin expression, and this cannot be compensated for by the expression of activating molecules such as activated R-Ras or the CD98 heavy chain [37]. Furthermore, talin knockdown prevents agonist-stimulated fibrinogen binding to megakaryocyte integrin $\alpha \operatorname{IIb} \beta 3$, suggesting that normal cellular activation of integrins also requires talin [37].

The talin F3 structure resembles a PTB (phosphotyrosine-binding) domain, which recognizes ligands containing $\beta$ turns formed by NPXY motifs [38]. NPXY motifs are well conserved in most integrin $\beta$ tails, and mutations that disrupt this motif perturb $\beta$-turn formation, inhibiting talin binding and interfering with integrin activation $[47,48]$. Similarly, mutations within the talin PTB-like domain prevent integrin $\beta$ tail binding and thereby block integrin activation $[37,49]$. Thus the integrin $\beta$ tail-talin interaction represents a general mechanism for integrin activation.

A major question is how talin binding activates integrins. When the ability of activating talin fragments to bind to different regions of the $\beta 3$ cytoplasmic domain was compared with that of non-activating talin fragments (i.e. the $\mathrm{F} 2$ domain) by monitoring the perturbation of specific NMR resonances of the $\beta$ tail, $\mathrm{F} 2-\mathrm{F} 3$ and F3 fragments, but not F2, showed distinct perturbation of the membrane-proximal region of the $\beta 3$ tail, suggesting the involvement of the $\beta 3$ tail membrane-proximal region in talin-mediated integrin activation [50]. As noted above, mutations in this region result in integrin activation. NMR studies suggest that direct disruption of $\alpha-\beta$ tail interaction by the talin head domain result in integrin activation [35]. In addition, F2-F3 and F3 also perturb the more distal region of the $\beta 3$ tail [49]. The membrane-distal 
region of the integrin $\beta$ tail provides a substantial fraction of the binding energy and has been suggested to contribute to integrin activation [51]. These data together suggest a two-step activation model: the talin head domain first recognizes the high-affinity binding site in the membrane-distal region, which provides a strong linkage between the talin and the integrin $\beta$ tail, and subsequently binds to a second lower-affinity membrane proximal site that is involved in $\alpha-\beta$ association, triggering separation of the tails and integrin activation (Figure 1) [49,52].

Many other PTB-domain-containing proteins bind to integrin $\beta$ tails in a similar fashion to talin $[49,53]$. Such proteins include Numb, Dok-1, ICAP-l $\alpha$ (integrin cytoplasmic domainassociated protein-l $\alpha$ ) and Kindlins [4,53], yet these proteins either fail to activate or are much less active than talin. Thus there must be additional unique features in the integrin-talin interaction that enable talin to cause activation [52]. A flexible loop between $\beta$-strands 1 and 2 of the F3 domain of talin accepts the side chains of the membrane-proximal region of the integrin $\beta$ tail. This mobile loop is absent from other PTB-domain-containing proteins, which implies that this may be the unique feature that distinguishes talin from other PTB-domaincontaining proteins in its ability to activate integrins. Furthermore, a mutation within this loop blocks talin binding to the membrane-proximal region and hinders integrin activation. In addition, when the talin $\mathrm{F} 3$ domain engages the $\beta$ membrane-proximal region, additional favourable electrostatic contacts between the F3 and the lipid headgroups of the membrane bilayer could stabilize further the talin $-\beta$ tail association. Mutation of one of the predicted contact residues in talin F3 also blocked activation. These data suggest that the formation of a complex between integrin $\beta$ tail membrane-proximal helix and the talin F3 domain, together with the favourable electrostatic contacts between the talin F3 and the lipid membrane, contribute to the energy required to stabilize the integrin-activated state [52]. Recent studies show that two other FERM-domain-containing proteins, MIG-2 (mitogen-inducible gene 2) and radixin, interact with the cytoplasmic tails of $\beta 1$ and $\beta 3$ and of $\beta 2$ respectively [54,55]. Furthermore, those studies indicate that these interactions may have context-dependent roles in integrin activation $[54,55]$. Thus, although talin is an important player in integrin activation mechanisms, the possibility remains that other integrin tail-binding proteins can substitute for talin.

\section{Regulation of integrin activation}

As noted above, numerous different signalling pathways can regulate integrin activation, and talin binding to the $\beta$ tail is often a final step. The issue now is to understand how these different signalling pathways intersect with talin binding.

Previous studies have identified Rap1 GTPase as a potent activator of integrins [56-58]. Many cytokines and growth factors promote integrin-dependent cell adhesion through the activation of Rap1 [57]. Furthermore, Rap1 regulates integrins that are associated with the actin cytoskeleton, such as integrins of the $\beta 1, \beta 2$ and $\beta 3$ family [59]. In patients with LAD-III (leucocyte adhesion deficiency III) who suffer from defects in leucocyte and platelet integrin activation, $\beta 1, \beta 2$ and $\beta 3$ integrins are expressed at normal levels. Cell from these patients are impaired in their abilities to bind to integrin ligands with high affinity in response to agonists $[60,61]$. Although expression of Rap1 and talin are normal in these patients, a mutation in CalDAG-GEFI $\left(\mathrm{Ca}^{2+}\right.$ diacylglycerol guanine-nucleotide-exchange factor I), which is a key Rap1/2 GEF (guanine-nucleotide-exchange factor) [60], is associated with LAD-III. Similarly, CalDAG-GEFI ${ }^{-1-}$ mice exhibit defects in activation of platelet and leucocyte $\beta 1, \beta 2$ and $\beta 3$ integrins and therefore impaired inflammatory response and lack of thrombus formation [61]. These findings together reveal that CalDAG-GEFI is a critical regulator of inside-out integrin activation in human T-lymphocytes, neutrophils and platelets, and emphasized the importance of Rap1 signalling pathways [60,61]. 
In the last few years, many Rap1 effectors have been identified. Among these, RIAM (Rap1GTP-interacting adaptor molecule) [59,62] is clearly implicated. Overexpression of RIAM induced the active conformation of integrins and enhanced cell adhesion, whereas depleting RIAM eliminated adhesion mediated by Rap1 [62]. Cell-type-specificity of integrin-affinity regulation by these signalling pathways is probably due to variations in expression of these GTPases or of the upstream and/or downstream elements that link them to integrin activation. Recent work has ordered a pathway from agonist stimulation to integrin activation for the first time, using a synthetic approach to reconstruct an integrin activation pathway in $\mathrm{CHO}$ cells (Figure 2) [63]. The central finding was that Rap1 induces formation of an integrin-activation complex containing RIAM and talin, which in turn leads to the unmasking of the integrinbinding site on talin; a critical, final, step in integrin activation. Moreover, these key components of the pathway, Rap1, RIAM and talin, are widely used in many cellular contexts and with various integrins [63]. $\alpha \mathrm{IIb} \beta 3$ is a prototypic integrin, and many of the principles of integrin function established by early studies with this integrin have proved to be widely applicable across the entire integrin family [63]. Platelet agonists, including PMA, thrombin, $\mathrm{ADP}$ and collagen, stimulate increased affinity of $\alpha \mathrm{IIb} \beta 3$ integrin in platelets; these agonists have failed to activate recombinant $\alpha \mathrm{IIb} \beta 3$ expressed in CHO cells or several other nucleated cells $[10,64]$. This puzzling observation has led to the reconstruction of an integrin-activation pathway in CHO cells [63]. This study illustrates the principle that variations in cellular abundance of the components of the integrin-activation complex such as talin or in their regulators such as $\mathrm{PKC} \alpha$ (protein kinase $\mathrm{C} \alpha$ ) can account for the cell-type-specificity of integrin activation [63]. Moreover, this reconstructed model also provides a system that can be used to manipulate the signalling events involved in integrin activation and to integrate and rationalize the currently available literature, and to connect different agonists and signalling pathways that are known to control integrin activation [63]. Similarly, it will allow for quantitative and mutational analyses of signalling pathways that regulate integrin activation. The analysis may be extended further to agonist receptors [e.g. PAR1 (protease-activated receptor 1)], G-proteins (e.g. Rap1, $\mathrm{G}_{\alpha \mathrm{q}}$ ) and tyrosine kinases (e.g. Tec kinases) that have been implicated in integrin activation.

\section{References}

1. Campbell ID, Ginsberg MH. The talin-tail interaction places integrin activation on FERM ground. Trends Biochem Sci 2004;29:429-435. [PubMed: 15362227]

2. Ginsberg MH, Partridge A, Shattil SJ. Integrin regulation. Curr Opin Cell Biol 2005;17:509-516. [PubMed: 16099636]

3. van der Flier A, Sonnenberg A. Function and interactions of integrins. Cell Tissue Res 2001;305:285298. [PubMed: 11572082]

4. Calderwood DA. Integrin activation. J Cell Sci 2004;117:657-666. [PubMed: 14754902]

5. Williams MJ, Hughes PE, O'Toole TE, Ginsberg MH. The inner world of cell adhesion: integrin cytoplasmic domains. Trends Cell Biol 1994;4:109-112. [PubMed: 14731732]

6. Hynes RO. Integrins: versatility, modulation, and signaling in cell adhesion. Cell 1992;69:11-25. [PubMed: 1555235]

7. Qin J, Vinogradova O, Plow EF. Integrin bidirectional signaling: a molecular view. PLoS Biol 2004;2:e169. [PubMed: 15208721]

8. Hynes RO. Integrins: bidirectional, allosteric signaling machines. Cell 2002;110:673-687. [PubMed: 12297042]

9. Liddington RC, Ginsberg MH. Integrin activation takes shape. J Cell Biol 2002;158:833-839. [PubMed: 12213832]

10. O’Toole TE, Katagiri Y, Faull RJ, Peter K, Tamura R, Quaranta V, Loftus JC, Shattil SJ, Ginsberg MH. Integrin cytoplasmic domains mediate inside-out signal transduction. J Cell Biol 1994;124:1047-1059. [PubMed: 7510712] 
11. Iber D, Campbell ID. Integrin activation: the importance of a positive feedback. Bull Math Biol 2006;68:945-956. [PubMed: 16802090]

12. Kim M, Carman CV, Springer TA. Bidirectional transmembrane signaling by cytoplasmic domain separation in integrins. Science 2003;301:1720-1725. [PubMed: 14500982]

13. Takagi J, Petre BM, Walz T, Springer TA. Global conformational rearrangements in integrin extracellular domains in outside-in and inside-out signaling. Cell 2002;110:599-611. [PubMed: 12230977]

14. Jin M, Andricioaei I, Springer TA. Conversion between three conformational states of integrin I domains with a C-terminal pull spring studied with molecular dynamics. Structure 2004;12:21372147. [PubMed: 15576028]

15. Nishida N, Xie C, Shimaoka M, Cheng Y, Walz T, Springer TA. Activation of leukocyte $\beta 2$ integrins by conversion from bent to extended conformations. Immunity 2006;25:583-594. [PubMed: 17045822]

16. Mould AP, Humphries MJ. Regulation of integrin function through conformational complexity: not simply a knee-jerk reaction? Curr Opin Cell Biol 2004;16:544-551. [PubMed: 15363805]

17. Shimaoka M, Lu C, Salas A, Xiao L, Takagi J, Springer TA. Stabilizing the integrin $\alpha \mathrm{M}$ inserted domain in alternative conformations with a range of engineered disulfide bonds. Proc Natl Acad Sci USA 2002;99:16737-16741. [PubMed: 12466503]

18. Zhu J, Boylan B, Luo BH, Newman PJ, Springer TA. Tests of the extension and deadbolt models of integrin activation. J Biol Chem 2007;282:11914-11920. [PubMed: 17301049]

19. Adair BD, Xiong JP, Maddock C, Goodman SL, Arnaout MA, Yeager M. Three-dimensional EM structure of the ectodomain of integrin $\alpha \mathrm{V} \beta 3$ in a complex with fibronectin. J Cell Biol 2005;168:1109-1118. [PubMed: 15795319]

20. Xiong JP, Stehle L, Goodman SL, Arnaout MA. New insights into the structural basis of integrin activation. Blood 2003;102:1155-1159. [PubMed: 12714499]

21. Luo BH, Springer TA. Integrin structures and conformational signaling. Curr Opin Cell Biol 2006;18:579-586. [PubMed: 16904883]

22. Humphries MJ, McEwan PA, Barton SJ, Buckley PA, Bella J, Mould AP. Integrin structure: heady advances in ligand binding, but activation still makes the knees wobble. Trends Biochem Sci 2003;28:313-320. [PubMed: 12826403]

23. Arnaout MA, Mahalingam B, Xiong JP. Integrin structure, allostery, and bidirectional signaling. Annu Rev Cell Dev Biol 2005;21:381-410. [PubMed: 16212500]

24. Luo BH, Carman CV, Springer TA. Structural basis of integrin regulation and signaling. Annu Rev Immunol 2007;25:619-647. [PubMed: 17201681]

25. Stefansson A, Armulik A, Nilsson I, von Heijne G, Johansson S. Determination of N- and C-terminal borders of the transmembrane domain of integrin subunits. J Biol Chem 2004;279:21200-21205. [PubMed: 15016834]

26. Gottschalk KE, Adams PD, Brunger AT, Kessler H. Transmembrane signal transduction of the $\alpha \operatorname{Ilb} \beta 3$ integrin. Protein Sci 2002;11:1800-1812. [PubMed: 12070332]

27. Luo BH, Carman CV, Takagi J, Springer TA. Disrupting integrin transmembrane domain heterodimerization increases ligand binding affinity, not valency or clustering. Proc Natl Acad Sci USA 2005;102:3679-3684. [PubMed: 15738420]

28. Luo BH, Springer TA, Takagi J. A specific interface between integrin transmembrane helices and affinity for ligand. PLoS Biol 2004;2:e153. [PubMed: 15208712]

29. Partridge AW, Liu S, Kim S, Bowie JU, Ginsberg MH. Transmembrane domain helix packing stabilizes integrin $\alpha \mathrm{IIb} \beta 3$ in the low affinity state. J Biol Chem 2005;280:7294-7300. [PubMed: 15591321]

30. Hughes PE, O’Toole TE, Ylanne J, Shattil SJ, Ginsberg MH. The conserved membrane-proximal region of an integrin cytoplasmic domain specifies ligand binding affinity. J Biol Chem 1995;270:12411-12417. [PubMed: 7759482]

31. Ma YQ, Yang J, Pesho MM, Vinogradova O, Qin J, Plow EF. Regulation of integrin $\alpha \mathrm{IIb} \beta 3$ activation by distinct regions of its cytoplasmic tails. Biochemistry 2006;45:6656-6662. [PubMed: 16716076] 
32. Hughes PE, Diaz-Gonzalez F, Leong L, Wu C, McDonald JA, Shattil SJ, Ginsberg MH. Breaking the integrin hinge: a defined structural constraint regulates integrin signaling. J Biol Chem 1996;271:6571-6574. [PubMed: 8636068]

33. O'Toole TE, Mandelman D, Forsyth J, Shattil SJ, Plow EF, Ginsberg MH. Modulation of the affinity of integrin $\alpha \operatorname{IIb} \beta 3$ (GPIIb-IIIa) by the cytoplasmic domain of $\alpha$ IIb. Science 1991;254:845-847. [PubMed: 1948065]

34. Lu C, Takagi J, Springer TA. Association of the membrane proximal regions of the $\alpha$ and $\beta$ subunit cytoplasmic domains constrains an integrin in the inactive state. J Biol Chem 2001;276:1464214648. [PubMed: 11279101]

35. Vinogradova O, Velyvis A, Velyviene A, Hu B, Haas L, Plow E, Qin J. A structural mechanism of integrin $\alpha \mathrm{IIb} \beta 3$ "inside-out" activation as regulated by its cytoplasmic face. Cell 2002;110:587-597. [PubMed: 12230976]

36. Takagi J, Erickson HP, Springer TA. C-terminal opening mimics 'inside-out' activation of integrin $\alpha 5 \beta 1$. Nat Struct Biol 2001;8:412-416. [PubMed: 11323715]

37. Tadokoro S, Shattil SJ, Eto K, Tai V, Liddington RC, de Pereda JM, Ginsberg MH, Calderwood DA. Talin binding to integrin $\beta$ tails: a final common step in integrin activation. Science 2003;302:103106. [PubMed: 14526080]

38. Calderwood DA, Yan B, de Pereda JM, Alvarez BG, Fujioka Y, Liddington RC, Ginsberg MH. The phosphotyrosine binding-like domain of talin activates integrins. J Biol Chem 2002;277:21749_ 21758. [PubMed: 11932255]

39. Calderwood DA, Zent R, Grant R, Rees DJ, Hynes RO, Ginsberg MH. The talin head domain binds to integrin $\beta$ subunit cytoplasmic tails and regulates integrin activation. $\mathrm{J}$ Biol Chem 1999;274:28071-28074. [PubMed: 10497155]

40. Kuo JC, Wang WJ, Yao CC, Wu PR, Chen RH. The tumor suppressor DAPK inhibits cell motility by blocking the integrin-mediated polarity pathway. J Cell Biol 2006;172:619-631. [PubMed: 16476779]

41. Franco SJ, Rodgers MA, Perrin BJ, Han J, Bennin DA, Critchley DR, Huttenlocher A. Calpainmediated proteolysis of talin regulates adhesion dynamics. Nat Cell Biol 2004;6:977-983. [PubMed: 15448700]

42. Lim J, Wiedemann A, Tzircotis G, Monkley SJ, Critchley DR, Caron E. An essential role for talin during $\alpha \mathrm{M} \beta 2$-mediated phagocytosis. Mol Biol Cell 2007;18:976-985. [PubMed: 17202407]

43. Tremuth L, Kreis S, Melchior C, Hoebeke J, Ronde P, Plancon S, Takeda K, Kieffer N. A fluorescence cell biology approach to map the second integrin-binding site of talin to a 130-amino acid sequence within the rod domain. J Biol Chem 2004;279:22258-22266. [PubMed: 15031296]

44. Petrich BG, Fogelstrand P, Partridge AW, Yousefi N, Ablooglu AJ, Shattil SJ, Ginsberg MH. The antithrombotic potential of selective blockade of talin-dependent integrin $\alpha \mathrm{IIb} \beta 3$ (platelet GPIIb-IIIa) activation. J Clin Invest 2007;117:2250-2259. [PubMed: 17627302]

45. Critchley DR. Focal adhesions: the cytoskeletal connection. Curr Opin Cell Biol 2000;12:133-139. [PubMed: 10679361]

46. Rees DJ, Ades SE, Singer SJ, Hynes RO. Sequence and domain structure of talin. Nature 1990;347:685-689. [PubMed: 2120593]

47. O'Toole TE, Ylanne J, Culley BM. Regulation of integrin affinity states through an NPXY motif in the $\beta$ subunit cytoplasmic domain. J Biol Chem 1995;270:8553-8558. [PubMed: 7721755]

48. Ulmer TS, Yaspan B, Ginsberg MH, Campbell ID. NMR analysis of structure and dynamics of the cytosolic tails of integrin $\alpha \operatorname{Ilb} \beta 3$ in aqueous solution. Biochemistry 2001;40:7498-7508. [PubMed: 11412103]

49. Garcia-Alvarez B, de Pereda JM, Calderwood DA, Ulmer TS, Critchley D, Campbell ID, Ginsberg MH, Liddington RC. Structural determinants of integrin recognition by talin. Mol Cell 2003;11:4958. [PubMed: 12535520]

50. Ulmer TS, Calderwood DA, Ginsberg MH, Campbell ID. Domain-specific interactions of talin with the membrane-proximal region of the integrin $\beta 3$ subunit. Biochemistry 2003;42:8307-8312.

[PubMed: 12846579] 
51. Vinogradova O, Vaynberg J, Kong X, Haas TA, Plow EF, Qin J. Membrane-mediated structural transitions at the cytoplasmic face during integrin activation. Proc Natl Acad Sci USA 2004;101:4094-4099. [PubMed: 15024114]

52. Wegener KL, Partridge AW, Han J, Pickford AR, Liddington RC, Ginsberg MH, Campbell ID. Structural basis of integrin activation by talin. Cell 2007;128:171-182. [PubMed: 17218263]

53. Calderwood DA, Fujioka Y, de Pereda JM, Garcia-Alvarez B, Nakamoto L, Margolis B, McGlade CJ, Liddington RC, Ginsberg MH. Integrin $\beta$ cytoplasmic domain interactions with phosphotyrosinebinding domains: a structural prototype for diversity in integrin signaling. Proc Natl Acad Sci USA 2003;100:2272-2277. [PubMed: 12606711]

54. Shi X, Ma YQ, Tu Y, Chen K, Wu S, Fukuda K, Qin J, Plow EF, Wu C. The MIG-2/integrin interaction strengthens cell-matrix adhesion and modulates cell motility. J Biol Chem 2007;282:20455-20466. [PubMed: 17513299]

55. Tang $\mathrm{P}, \mathrm{Cao} \mathrm{C}, \mathrm{Xu} \mathrm{M}$, Zhang L. Cytoskeletal protein radixin activates integrin $\alpha \mathrm{M} \beta 2$ by binding to its cytoplasmic tail. FEBS Lett 2007;581:1103-1108. [PubMed: 17321526]

56. Alberts, B.; Johnson, A.; Lewis, J.; Raff, M.; Roberts, K.; Walter, P. Molecular Biology of the Cell. Garland Science; New York: 2002. Cell junctions, cell adhesion, and the extracellular matrix.

57. Kinbara K, Goldfinger LE, Hansen M, Chou FL, Ginsberg MH. Ras GTPases: integrins' friends or foes? Nat Rev Mol Cell Biol 2003;4:767-776. [PubMed: 14570053]

58. Katagiri K, Hattori M, Minato N, Irie S, Takatsu K, Kinashi T. Rap1 is a potent activation signal for leukocyte function-associated antigen 1 distinct from protein kinase $\mathrm{C}$ and phosphatidylinositol-3OH kinase. Mol Cell Biol 2000;20:1956-1969. [PubMed: 10688643]

59. Bos JL. Linking Rap to cell adhesion. Curr Opin Cell Biol 2005;17:123-128. [PubMed: 15780587]

60. Pasvolsky R, Feigelson SW, Kilic SS, Simon AJ, Tal-Lapidot G, Grabovsky V, Crittenden JR, Amariglio N, Safran M, Graybiel AM, et al. A LAD-III syndrome is associated with defective expression of the Rap-1 activator CalDAG-GEFI in lymphocytes, neutrophils, and platelets. J Exp Med 2007;204:1571-1582. [PubMed: 17576779]

61. Bergmeier W, Goerge T, Wang HW, Crittenden JR, Baldwin AC, Cifuni SM, Housman DE, Graybiel AM, Wagner DD. Mice lacking the signaling molecule CalDAG-GEFI represent a model for leukocyte adhesion deficiency type III. J Clin Invest 2007;117:1699-1707. [PubMed: 17492052]

62. Lafuente EM, van Puijenbroek AA, Krause M, Carman CV, Freeman GJ, Berezovskaya A, Constantine E, Springer TA, Gertler FB, Boussiotis VA. RIAM, an Ena/VASP and profilin ligand, interacts with Rap1-GTP and mediates Rap1-induced adhesion. Dev Cell 2004;7:585-595. [PubMed: 15469846]

63. Han J, Lim CJ, Watanabe N, Soriani A, Ratnikov B, Calderwood DA, Puzon-McLaughlin W, Lafuente EM, Boussiotis VA, Shattil SJ, Ginsberg MH. Reconstructing and deconstructing agonist-induced activation of integrin $\alpha \mathrm{IIb} \beta 3$. Curr Biol 2006;16:1796-1806. [PubMed: 16979556]

64. O'Toole TE, Loftus JC, Du XP, Glass AA, Ruggeri ZM, Shattil SJ, Plow EF, Ginsberg MH. Affinity modulation of the $\alpha \mathrm{IIb} \beta 3$ integrin (platelet GPIIb-IIIa) is an intrinsic property of the receptor. Cell Regul 1990;1:883-893. [PubMed: 2100193]

\section{Abbreviations used}

\section{CaIDAG-GEFI}

$\mathrm{Ca}^{2+}$ diacylglycerol guanine-nucleotide-exchange factor I

CHO

Chinese-hamster ovary

FERM

4.1/ezrin/radixin/moesin

FRET

Förster resonance energy transfer

\section{GEF}

Biochem Soc Trans. Author manuscript; available in PMC 2008 November 26. 
guanine-nucleotide-exchange factor

LAD-III

leucocyte adhesion deficiency III

PKC

protein kinase $\mathrm{C}$

PTB

phosphotyrosine-binding

RIAM

Rap1-GTP-interacting adaptor molecule 
A.

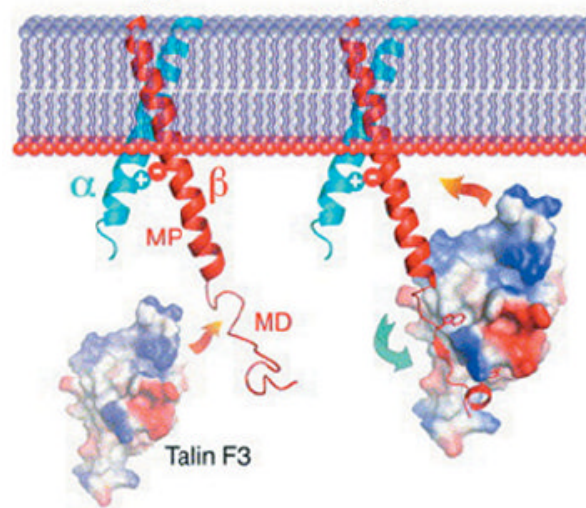

c.

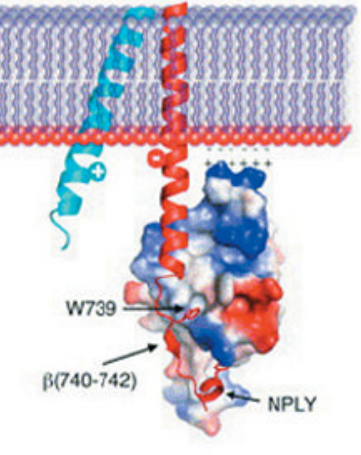

Figure 1. Model of talin-induced integrin activation

Left: the talin F3 domain (surface representation; coloured by charge), freed from its autoinhibitory interactions in the full-length protein, becomes available for binding to the integrin. Middle: F3 engages the membrane-distal (MD) part of the $\beta 3$-integrin tail (in red), which becomes ordered, but the $\alpha-\beta$ integrin interactions that hold the integrin in the lowaffinity conformation remain intact. Right: in a subsequent step, F3 engages the membraneproximal (MP) portion of the $\beta 3$ tail while maintaining its MD interactions. Consequences of this additional interaction are: (i) destabilization of the putative integrin salt bridge; (ii) stabilization of the helical structure of the MP region; and (iii) electrostatic interactions between F3 and the acidic lipid headgroups. The net result is a change in the position of the transmembrane helix, which is continuous with the MP $\beta$ tail helix. This position change causes a packing mismatch with the $\alpha \mathrm{IIb}$ transmembrane helix, separation or reorientation of the integrin tails and activation (inset). Mutants of F3 that have compromised interactions with the MP region and other PTB domains that lack an MP-binding site stall at point B, consistent with their dominant-negative behaviour. Reprinted from Cell, 128, Wegener, K.L., Partridge, A.W., Han, J., Pickford, A.R., Liddington, R.C., Ginsberg, M.H. and Campbell, I.D., 'Structural basis of integrin activation by talin', pp. 171-182. (C) 2007, with permission from Elsevier. 


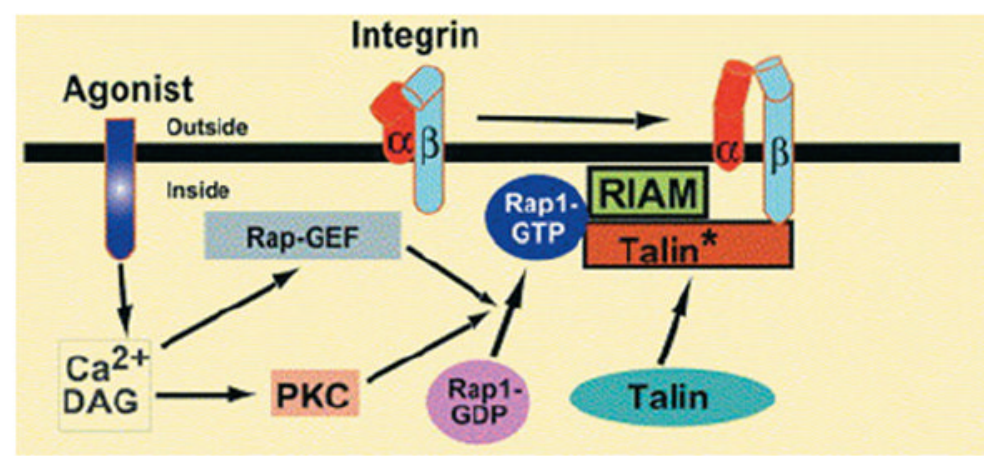

Figure 2. Connecting agonist stimulation to integrin activation

Depicted are core connections between agonists and integrins. Agonist receptors (e.g. Gprotein-coupled receptors, tyrosine-kinase-coupled receptors) induce the formation of DAG (diacylglycerol) and increased $\mathrm{Ca}^{2+}$, leading to the activation and/or translocation of active GTP-bound Rap1 to the plasma membrane via activation of PKC or a Rap-GEF. At the plasma membrane, activated Rap interacts with RIAM, leading to the recruitment of talin to form the integrin-activation complex, thus unmasking the integrin-binding site on talin, leading to integrin activation. Reprinted from Curr. Biol., 16, Han, J., Lim, C.J., Watanabe, N., Soriani, A., Ratnikov, B., Calderwood, D.A., Puzon-McLaughlin, W., Lafuente, E.M., Boussiotis, V.A., Shattil, S.J. and Ginsberg, M.H., 'Reconstructing and deconstructing agonist-induced activation of integrin $\alpha \mathrm{IIb} \beta 3$ ', pp. 1796-1806. (C) 2006, with permission from Elsevier. 